\section{Measurement of Paper Porosity}

\author{
by D. Butters
}

The author's supplementary comment

on the original publication

which appeared on pp. 307 to 311

of volume 5 of the

"Beiträge zur Tabakforschung" (1969-1970)

I refer to the comments of Dr. Lipp of Martin Brinkmann AG., published with my paper in „Beiträge zur Tabakforschung", Volume 5, Issue No. 6, December 1970.

It would seem to me that Dr. Lipp's points might be summarized as follows:

1. The instrument developed by Brinkmann and now manufactured and sold by Heinrich Borgwaldt has gained wide acceptance.

2. This instrument has the advantages of a metal-tometal surface contact in the clamp, and will permit measurement of larger areas of paper.

3. Definitions have been proposed and accepted as long ago as 1963, and such definitions and apparatus have been used both in the cigarette industry and the paper industry, and have proved to be most satisfactory.

4. One should not convert the definition to working units.

Might I, therefore, be allowed to comment on these points?

I. I most certainly agree that the Borgwaldt instrument is much superior to the traditional cigarette industry instruments, most of which involve falling water columns, and are totally unsatisfactory for our present needs (e. g. Greiner).

Unfortunately, its acceptance and usage is not worldwide, and many laboratories consider that it does not fully meet their needs. (See pt. 2 below.)

2. In the instrument I described, the sample clamps have been so designed that there is no deformation of the test area. They also have the great advantage of ease and speed of operation. It is for this reason that I have been asked to supply sample clamps from the Wiggins Teape instrument to be fitted to the Borgwaldt instrument!

3. Many definitions have been proposed and gained $\&$ acceptance; this surely is true of many properties of 4. materials for use in many industries. Unfortunately, it is a fact that no definition of "air permeability" has been universally accepted by the cigarette industry, or by that part of the paper industry, which supplies cigarette tissues. In practice, both the Borgwaldt and Wiggins Teape instruments have been accepted as standards by a number of different cigarette manufacturers and paper manufacturers, and the "standard" definition, which I proposed, is now accepted by the paper makers' standards organizations of most nations, as their official standard. The importance of standardization between industries should be recognized.

We seem to have confused "working" and "standard" definitions, conditions and units. There are many practical reasons for using "working" units and conditions, which differ from the "standard". For properly designed instruments, the difference should be manifest, only in orders of magnitude of the constants. CORESTA S.M. 10 and the definition I proposed differ only in this respect, and recent work has shown a highly significant correlation between the results of the respective instruments.

I would, therefore, submit that both instruments better meet the requirements of our industries than many of those in current use, and am unable to accept Dr. Lipp's conclusions. 